
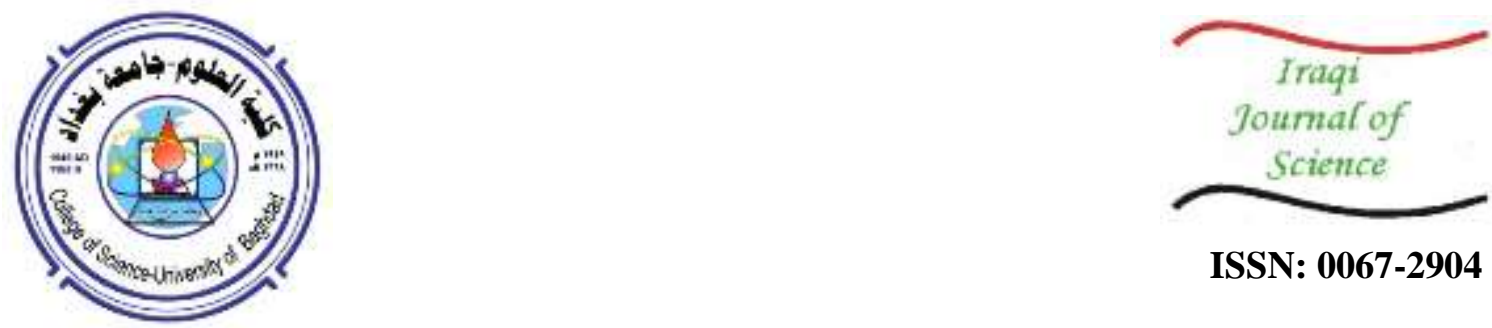

ISSN: 0067-2904

\title{
Study on lung infections of patients with cancer under chemotherapy
}

\author{
Safana Abdul Sattar*, Nawar Al Mallah \\ National Cancer Research Center/ University of Baghdad, Baghdad, Iraq
}

\begin{abstract}
The aim of this study is to assess the prevalence of lung infections among a group of hospitalized cancer patients who received chemotherapy as well as to describe a population of these patients. The clinical data and demographic information were collected from the archived files of in-patients referred to hematology center / Baghdad Teaching Hospital / Medical City , ministry of health, Iraq during the period of 2018.

This study was carried out on 250 patients with different types of cancer ,they were mostly of age group (40 - 49) $59 / 250$ (23.6)\%, (14-19) 49/250 (19.6\%) and (60-69) 41/250(16.4\%). The patients had two major types of hematological malignancies: leukemia $109 / 250(43.6 \%$ ) and lymphoma $105 / 250(42 \%)$, only $36 / 250$ $(14.4 \%)$ of the patients had other types of cancer which were distributed as : $26 / 250$ ( $10.4 \%$ ) microangiopathic and $10 / 250$ (4\%) Multiple myelomoa. Statistically, there was significant correlation between age parameter and types of cancer in $\mathrm{p}<0.05$ ( $\mathrm{p}$ value : 0.000 ).

Patients with positive Lung infections, as recorded on their medical reports, were not in high frequency and found only in 48/250(19.2\%) of the cases which were mostly shown in patients with leukemia 28/48( $58.3 \%$ ) .In spite of that there was no significant correlation between lung infections and type of cancer. The higher percentage of patients, who admitted to the women wards of Baghdad hospital, came from Baghdad city 132/250(52.8\%) and diyala governorate $45 / 250(18 \%)$. The married women were $173 / 250(69.2 \%)$ and mostly they were housewives $200 / 250(80 \%)$. The illiteracy was in $67 / 250(26.8 \%$ ) of patients.

Low frequent lung infections as resulted during this study could be because of the good control of infections by giving suitable antibiotic drugs for the bacterial infections but most of patients with positive cases may be infected with viruses or fungi, which are difficult to diagnose and treat. These infections occurred due to the immune defects induced by chemotherapy treatments. So the greatest hope for the future is the availability of more targeted anticancer drugs that have fewer sideeffects on the immune system.
\end{abstract}

Keywords: lung infection, chemotherapy, patients with cancer, Iraq

$$
\begin{aligned}
& \text { دراسة على التهابات الرئة لمرضى السرطان تحت العلاج الكيميائي } \\
& \text { سفانة عبد الستار ياسين**، نوار عبد الغني الملاح }
\end{aligned}
$$

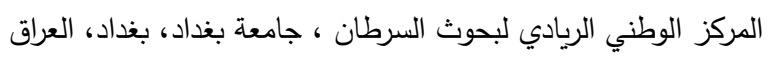

$$
\begin{aligned}
& \text { ان الهدف من هذه الدراسة هو تقييم مدى انتشار التهابات الرئة بين مجموعة من مرضى السرطان }
\end{aligned}
$$

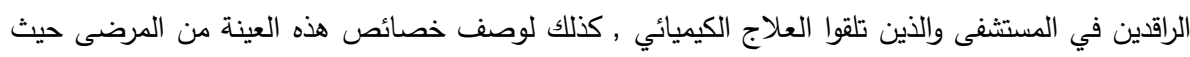




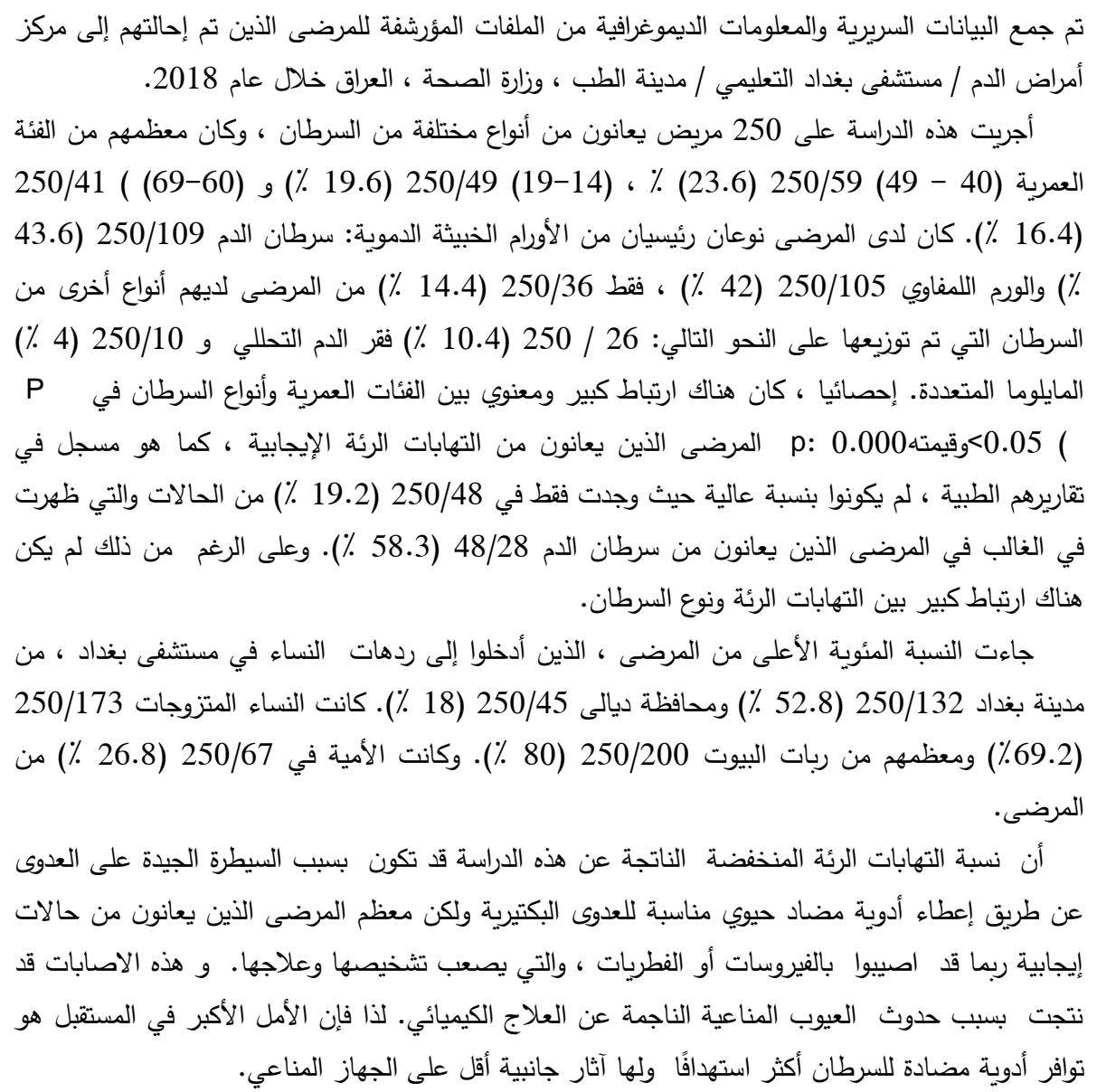

\section{Introduction}

Cancer patients are more likely to get infections. Pneumonia is one of the most frequent type of infection in this group [1]. So Malignancy is considered a risk factor in the development of such infection [2]. Lung infections can be severe consequences of chemotherapy-induced immune defects [3].

The newly diagnosed patient with cancer prior to chemotherapy and those between cancer therapies have a relatively intact and functional immune system. The primary respiratory infections in this relatively nonimmunocompromised phase include those caused by pathogens common to the general public [4].

Most infections are caused by bacteria ( most commonly: Pseudomonas aeruginosa, Stenotrophomonas maltophilia, and Nocardia species ) [3] , but viruses are being increasingly identified (eg, respiratory syncytial virus, parainfluenza virus, influenza virus A and B, and cytomegalovirus). However, during wintertime, community outbreaks of influenza virus and respiratory synctial virus (RSV) can cause severe pneumonia and death in neutropenic leukemic patients who recently received chemotherapy [5].

Some patients are prone to lung infections because of the immune suppression caused by their cancers, such as multiple myeloma and chronic lymphocytic leukemia, the encapsulated organisms such as pneumococcus and $H$. influenzae commonly cause bronchitis and pneumonia [4]

Diagnosis is difficult and frequently time-consuming. Treatment can be ineffective for many patients, particularly those with fungal infection( especially Aspergillus, Fusarium, and Mucorales species [3]. On the other hand, Candida colonization of the upper respiratory tract is quite common in patients with cancer. Most cases of Candida cultured from sputum or bronchoalveolar lavage is due to upper airway colonization and not pneumonia[6].

Both cancer and its treatment induce derangements of innate and adaptive immune function. Leukocyte depletion, dysregulated inflammation, impaired pathogen recognition, and graft-versus-host responses contribute to cancer patients' tremendous susceptibility to lower respiratory tract infections. 
Functional and anatomical defects frequently coexist in cancer patients. Further, recurrent healthcare encounters that are typical among cancer patients promote exposure to nosocomial and drug- resistant pathogens [7].

When evaluating pneumonia in patients with cancer, determining the level of immunosuppression, the previous exposure to antimicrobials, the duration of the illness, the presenting symptoms, and the radiographic pattern will better predict the suspected pathogens or noninfectious causes. Following this determination, the appropriate antimicrobials can be instituted empirically. Knowing the three phases of cancer therapy and their associated respiratory complications should improve the accuracy of predicting the etiology of pulmonary pathology [4].

\section{Method}

The purpose of this study is to evaluate the prevalence of lung infection among cancer patients receiving chemotherapy for more than two weeks at least The current study consists of 250 hospitalized cancer patients, aged from 14 to 77 years old. Data obtained from the archived files of in-patients admitted to hematology center (women wards) / Baghdad Teaching Hospital / Medical City , Ministry of Health, Iraq during the period of 2018.

The patients were all diagnosed as having cancer, some of them presenting with pneumonia, and treated at the same institution. This was all completed by the oncologists, who also validated all lung infections. The diagnosis of pneumonia was based on the presence of selected clinical features (e.g., cough, fever, sputum production and chest pain) and supported by imaging of the lung in the first $48 \mathrm{~h}$ of hospital admission. Data on pneumonia diagnosis and its related features were obtained retrospectively by chart review using a standardized form for data abstraction. Microbiological confirmation was not a compulsory inclusion criterion for the study.

The clinical data were analyzed using statistical package of social (SPSS) for version 10 . Differences in proportions were assessed by Chi-square test. $P$-values $<0.05$ were considered statistically significant (social sciences statistics).

The incidence rate of lung infections was detected and its relationship with types of cancer was studied as well . In addition, the relationship between age groups and types of cancer was investigated patients' information was also collected to describe the population of these patients such as ,age, residence, marital status, work, culture and certificate holder.

The present study was approved by the Iraqi national cancer research center /University of Baghdad, Iraq ( 2/5/2018).

\section{Results:}

During the study period, some of admitted patients with a definite diagnosis of cancer were presenting with pneumonia .The results of the analyzed patients' data showed that patients were mostly of age group (40 - 49) 59 / 250 (23.6)\%, (14-19) $49 / 250$ (19.6\%) and (60-69) 41/ 250(16.4\%) . The marital status of patients showed that $173 / 250(69.2 \%)$ of the women were married and mostly they were housewives $200 / 250(80 \%)$. The illiteracy was in $67 / 250(26.8 \%$ ) of patients as shown in (Table-1). The higher percentage of patients, who admitted to the women wards of Baghdad hospital ,came from Baghdad city 132/250(52.8\%) and Diyala governorate 45/250(18\%) see (Table-2 ).

The patients had two major types of hematological malignancies: leukemia 109/250(43.6\%) and lymphoma $105 / 250(42 \%)$, only $36 / 250$ (14.4\%) of the patients had other types of cancer which were distributed as : 26/250( $10.4 \%$ ) microangiopathic and $10 / 250(4 \%)$ Multiple myeloma as shown in ( Table -1).

Table 1-Age group, marital status, certificate holder, patients work, patients and types of cancer,

\begin{tabular}{|c|c|c|c|}
\hline & & Frequency & Percent \\
\hline \multirow{6}{*}{ 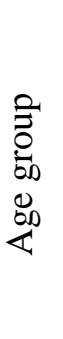 } & less than 20 & 49 & 19.6 \\
\hline & $20-29$ & 20 & 8.0 \\
\hline & 30-39 & 30 & 12.0 \\
\hline & $40-49$ & 59 & 23.6 \\
\hline & $50-59$ & 32 & 12.8 \\
\hline & $60-69$ & 41 & 16.4 \\
\hline
\end{tabular}




\begin{tabular}{|c|c|c|c|}
\hline & 70\&over & 19 & 7.6 \\
\hline & Total & 250 & 100.0 \\
\hline \multirow{4}{*}{ 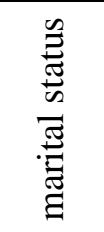 } & married & 173 & 69.2 \\
\hline & single & 55 & 22.0 \\
\hline & Other* & 22 & 8.8 \\
\hline & Total & 250 & 100.0 \\
\hline \multirow{5}{*}{ 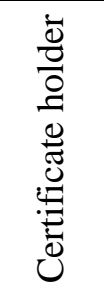 } & illiteracy & 67 & 26.8 \\
\hline & primary & 98 & 39.2 \\
\hline & secondry & 59 & 23.6 \\
\hline & university & 26 & 10.4 \\
\hline & Total & 250 & 100.0 \\
\hline \multirow{4}{*}{ 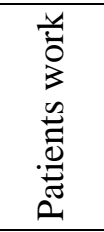 } & employee & 19 & 7.6 \\
\hline & housewife & 200 & 80.0 \\
\hline & student & 31 & 12.4 \\
\hline & Total & 250 & 100.0 \\
\hline \multirow{4}{*}{ 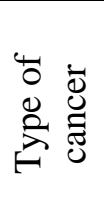 } & Lymphoma & 105 & 42.0 \\
\hline & Leukemia & 109 & 43.6 \\
\hline & Others $*$ & 36 & 14.4 \\
\hline & Total & 250 & 100.0 \\
\hline
\end{tabular}

others: 26/250( $10.4 \%)$ microangiopathic and $10 / 250(4 \%)$ Multiple myeloma

Table 2-patients residence

\begin{tabular}{|c|c|c|}
\hline Governorate & patients & Percent \\
\hline baghdad & 132 & 52.8 \\
diyala & 45 & 18.0 \\
qadisiyah & 10 & 4.0 \\
missan & 5 & 2.0 \\
theqar & 10 & 4.0 \\
kirkuk & 5 & 2.0 \\
waset & 8 & 3.2 \\
babil & 7 & 2.8 \\
karbala & 11 & 4.4 \\
muthana & 6 & 2.4 \\
salahaldeen & 4 & 1.6 \\
others & 7 & 2.8 \\
Total & 250 & 100.0 \\
\hline
\end{tabular}

Statistically ,there was a significant correlation between age group and type of cancer according to (social sciences statistics), the $P$ value was 0.000 at $\mathrm{P}<0.05$ (Table-3). 
Table 3-Correlation between age group and types of cancer

\begin{tabular}{|c|c|c|c|c|c|}
\hline \multirow{2}{*}{ age categories } & \multicolumn{3}{|c|}{ the type of disease } & \multirow{2}{*}{ Total } & \multirow{2}{*}{$* \mathrm{P}$ value } \\
\hline & lymphoma & leukemia & others & & \\
\hline less than 20 & 7 & 36 & 6 & 49 & \multirow{8}{*}{$\begin{array}{c}\text { Significant } p \\
\text { value }: 0.000 \text { at } \\
\mathrm{P}<0.05\end{array}$} \\
\hline $20-29$ & 16 & 3 & 1 & 20 & \\
\hline $30-39$ & 12 & 13 & 5 & 30 & \\
\hline $40-49$ & 24 & 30 & 5 & 59 & \\
\hline $50-59$ & 19 & 9 & 4 & 32 & \\
\hline $60-69$ & 17 & 14 & 10 & 41 & \\
\hline 70\&over & 10 & 4 & 5 & 19 & \\
\hline Total & 105 & 109 & 36 & 250 & \\
\hline
\end{tabular}

Patients with positive Lung infections, as recorded in their medical reports, were not in high frequency and found only in 48/250(19.2\%) of the cases which were mostly shown in patients with leukemia 28/48( $58.3 \%)$.In spite of that there was no significant correlation between lung infections and type of cancer ( $\mathrm{p}$ value .066 at $\mathrm{P}<0.05$ ) as seen in (Table-4).

Table 4-Relationship between lung infection and types of cancer

\begin{tabular}{|c|c|c|c|c|c|c|}
\hline \multirow{2}{*}{ Lung infection } & \multicolumn{3}{|c|}{ type of cancer } & \multirow{2}{*}{ Total } & \multirow{2}{*}{$\begin{array}{c}\text { Percent } \\
\%\end{array}$} & \multirow{2}{*}{ *P value } \\
\hline & lymphoma & leukemia & others & & & \\
\hline negative & 91 & 81 & 30 & 202 & 80.8 & \multirow{3}{*}{$\begin{array}{c}\text { no significant }(\mathrm{p} \text { value } \\
.066) \text { at } \mathrm{p}<0.05\end{array}$} \\
\hline positive & 14 & 28 & 6 & 48 & 19.2 & \\
\hline Total & 105 & 109 & 36 & 250 & 100 & \\
\hline
\end{tabular}

\section{Discussion}

pneumonia continues to be a major problem associated with significant morbidity and mortality in cancer patients. It is also one of the most serious infectious complications after chemotherapy treatment especially in patients who have hematological malignances with case fatality rates of 25 to $45 \%[8,9]$. Early mortality continues to be significant despite advances in supportive care $[10,11]$.

During this study, we evaluate the prevalence of lung infection among 250 patients, aged from 14 to 77 yrs. , with hematological cancer. These patients admitted to hematology center (women ward)/ Baghdad teaching hospital and receiving chemotherapy for more than two weeks at least. Most of patients came from Baghdad city 132/250(52.8\%) and diyala governorate 45/250(18\%). Married women were $173 / 250(69.2 \%)$ and most of them were housewives $200 / 250(80 \%)$. The illiteracy were in $67 / 250(26.8 \%)$ of patients .

The patients had two major types of hematological malignancies : leukemia 109/250(43.6\%) and lymphoma $105 / 250(42 \%)$, only $36 / 250$ (14.4\%) of the patients had other types of cancer which were distributed as : 26/250( $10.4 \%$ ) microangiopathic and 10/250 (4\%) Multiple myeloma. There was a significant relationship between cancer types and age group of patients, ( $\mathrm{p}$ value : 0.000 at $\mathrm{P}<0.05$ ), and these patients were mostly of age group (40 - 49) $59 / 250$ (23.6)\%, (14-19) $49 / 250$ (19.6\%) and (60-69) $41 / 250(16.4 \%)$.one study mentioned that within the first 15 years of life, marked differences are found in the age-distribution of various cancers [12]. Gradual increases with age are seen in the incidence of hematological malignances [13].

The current study showed that the incidence rate of pneumonia was low and found only in $48 / 250(19.2 \%)$ of patients . Although, there was no significant relationship between lung infections 
with type of cancer, but most of the positive cases of pneumonia were found in leukemic cases : $28 / 48(58.3 \%)$. The incidence of pneumonia syndrome in our study was similar to that of other studies $[8,14,15]$.

Although these findings are useful, it is important to recognize the limitations of this study because a diagnosis of pneumonia is difficult to establish with certainty in this population [16].Our findings are consistent with previous studies which showed that lung infection was among the serious infections, developing in hospitalized cancer patients receiving chemotherapy for more than two weeks $[14,15]$. Pulmonary complications can begin with the first dose of chemotherapy or, more commonly, develop after the course of therapy is completed. Older adults and those with comorbidities, a smoking history, pre-existing pulmonary disease, and receiving oxygen at high doses are at greater risk [17].

Many researchers have analyzed the factors associated with this infection and suggest that personalized treatment protocols can reduce mortality in this population. Until now, there was a consensus among the medical community that the majority of pneumonia cases in cancer patients were due to the immune system debility caused by the disease and anticancer drugs .In addition, the exposure to multiresistant bacteria, because of spending a lot of time in hospitals, can cause severe pulmonary infection [1].

Recent advances in our understanding of innate immunity may make pneumonia prevention feasible in selected high-risk populations [18]. Translation of these basic science advances into clinically effective interventions requires careful measurement of the incidence rate of pneumonia in the hematological cancer population and identification of its determinants [19].

Low frequent of lung infections as we resulted during this study could be because of the good control of infections by giving suitable antibiotic drugs for the bacterial infections and the patients with positive lung infections may due to viral or fungal causative agents, which are difficult to diagnose and treat. These infections usually occurred when the immune defects induced by chemotherapy treatments. so the greatest hope for the future is the availability of more targeted anticancer drugs that have fewer side-effects on the immune system.

More studies are required in this field, especially in Baghdad city because of limited published papers found during this study.

\section{References}

1. Ligia S. C. F., Rabello, Jose R. L. Silva, Luciano C. P. Azevedo, Ivens Souza, Viviane B. L. Torres, Maíra M. Rosolem, Thiago Lisboa, Marcio Soares, Jorge Salluh, I.F. 2015. Clinical Outcomes and Microbiological Characteristics of Severe Pneumonia in Cancer Patients:A Prospective Cohort Study. PLOS ONE; 10(3): e0120544

2. Vincent JL, Moreno R, Takala J, Willatts S, De Mendonça A. and Bruining H. 1996. The SOFA (Sepsis-related Organ Failure Assessment) score to describe organ dysfunction/failure. On behalf of the Working Group on Sepsis-Related Problems of the European Society of Intensive Care Medicine. pp: 707-10.

3. Vento S, Cainelli F. and Temesgen Z. 2008. Lung infections after cancer chemotherapy.Lancet Oncol.; 9(10): 982-992.

4. John, C. Ruckdeschel, MD, John Greene, MD, K. Eric Sommers, MD, and Karen K. Fields, MD. 2003. Respiratory infections in patients with cancer.Holland-Frei Cancer Medicine. 6th edition,NCBI BC Decker Inc. Bookshelf ID: NBK13540.

5. Yousuf, H.M., Englund, J. and Couch, R. 1997. Influenza among hospitalized adults with leukemia. Clin Infect Dis.; 24:1095-9.

6. Kontoyiannis, D.P, Reddy, BT., Torres HA. 2002. Pulmonary candidiasis in patients with cancer: an autopsy study. Clin Infect Dis.; 34: 400-3.

7. Scott, E., Evans, MD. and David E. Ost, MD, MPH. 2015. Pneumonia in the neutropenic cancer patient. Curr Opin Pulm Med.; 21(3): 260-271.

8. Cannas G, Pautas C, Raffoux E, Quesnel B, de Botton S, de Revel T, Reman O, Gardin C, Elhamri $\mathrm{M}$, Boissel N, et al. 2012. Infectious complications in adult acute myeloid leukemia: analysis of the Acute Leukemia French Association-9802 prospective multicenter clinical trial. Leuk Lymphoma; 53: 1068-1076. 
9. Rossini F, Verga M, Pioltelli P, Giltri G, Sancassani V, Pogliani EM, Corneo G. 2000 .Incidence and outcome of pneumonia in patients with acute leukemia receiving first induction therapy with anthracycline-containing regimens. Haematologica; 85: 1255-1260.

10. Appelbaum FR, Gundacker H, Head DR, Slovak ML, Willman CL, Godwin JE, Anderson JE, Petersdorf SH. 2006. Age and acute myeloid leukemia. Blood; 107: 3481-3485.

11. De Witte T, Suciu S, Verhoef G, Labar B, Archimbaud E, Aul C, Selleslag D, Ferrant A, Wijermans P, Mandelli F, et al. 2001 .Intensive chemotherapy followed by allogeneic or autologous stem cell transplantation for patients with myelodysplastic syndromes (MDSs) and acute myeloid leukemia following MDS. Blood; 98: 2326-2331.

12. Taghreid Kheder Mohammad, Asmaa Hashem Mahmood, Genan Fadel Elew and Saja Jehad. 2009.A study on the prevalence of acute leukemia among a group of Iraqi patients Al-Khalidi .Journal of Al-Nahrain University, 12(2): 107-112 Science 107.

13. Miller, R.W.; Young, J.L. and Novakovic, B. Cancer childhood .1995. Cancer Supplement. 75 (1): 395-405.

14. Specchia G, Pastore D, Carluccio P, Mele G, Montagna MT, Liso A, Rizzi R, Ianora AS, Liso V. 2003. Pneumonia in acute leukemia patients during induction therapy: experience in a single institution. Leuk Lymphoma; 44: 97-101.

15. Wilhelm M, Kantarjian HM, O’Brien S, Pierce S, Keating MJ, Freireich EJ, Estey EH. 1996. Pneumonia during remission induction chemotherapy in patients with AML or MDS. Leukemia ; 10: $1870-1873$.

16. American Thoracic Society; Infectious Diseases Society of America. 2005 .Guidelines for the management of adults with hospital-acquired, ventilator-associated, and healthcare-associated pneumonia. Am J Respir Crit Care Med.; 171: 388-416.

17. Debra Wood, RN ; Epting S. 2010. Managing the Respiratory Complications of Cancer. NY, ONS IOL 2009 Meeting

18. Clement CG, Evans SE, Evans CM, Hawke D, Kobayashi R, Reynolds PR, Moghaddam SJ, Scott BL, Melicoff E, Adachi R, et al. 2008 .Stimulation of lung innate immunity protects against lethal pneumococcal pneumonia in mice. Am J Respir Crit Care Med.; 177: 1322-1330.

19. Yoshida M, Akiyama N, Fujita H, Miura K, Miyatake J, Handa H, Kito K, Takahashi M, Shigeno $\mathrm{K}$, Kanda Y, et al. 2011. Analysis of bacteremia/fungemia and pneumonia accompanying acute myelogenous leukemia from 1987 to 2001 in the Japan Adult Leukemia Study Group. Int J Hematol.; 93: 66-73. 